\title{
CHIKUNGUNYA FEVER THERAPEUTIC CHALLENGE IN PRIMARY HEALTH CARE IN THE MUNICIPALITY OF TEIXEIRA DE FREITAS
}

\author{
Mellina da Silva Gonçalves ${ }^{1, \star}$, Luciana Barbosa Firmes Marinato ${ }^{1}$ \\ 1.Faculdade Vale do Cricaré, São Mateus (ES), Brazil. \\ *Corresponding author: melgef@hotmail.com
}

\section{BACKGROUND}

Chikungunya fever is a common arbovirus disease in tropical countries which became endemic in Brazil from 2014 onwards. Between 2018 and 2019, Bahia was one of the Brazilian states with the highest incidence of chikungunya fever, with the municipality of Teixeira de Freitas among the ten most affected cities in that period. This arbovirus usually evolves with disabling musculoskeletal chronicity, significantly reducing the quality of life of those infected. Furthermore, in these cases, the quality of care in primary health care is essential, as in addition to being the gateway to the treatment of chikungunya, it has the potential to reduce chronicity and the demands for specialized care. In this sense, this study aimed to understand the difficulties and challenges faced by family and community doctors in the city of Teixeira de Freitas in the therapeutic management of patients affected by chikungunya.

\section{METHODS}

This research, with a qualitative bias, used data from public health portals and the testimonies of $20 \%$ of family and community doctors who worked in basic health units with high chikungunya fever notification rates in 2018 and 2019 . Interviews were conducted in order to analyze the technical difficulties and challenges encountered by these professionals for the quality treatment of patients affected by this arbovirus.

\section{CONCLUSION}

As an intervention proposal to the results of this research, an instructional material aimed at family and community physicians was elaborated with a view to contributing efficiently and effectively to the treatment of patients affected by chikungunya.

\section{KEYWORDS}

Chikungunya fever, Primary health care, Family and community doctors. 